\title{
Areas Affected Most by the Students from the ICT Focused Technological Transformations and Its Effects on Education
}

\author{
Assist.Prof.Dr. Ahmet Naci Çoklar \\ Necmettin Erbakan University, Ahmet Kelesoglu Education Faculty, \\ Department of Computer Education and Instructional Technologies, Meram, Konya, Turkey \\ acoklar@konya.edu.tr
}

\section{Doi:10.5901/mjss.2013.v4n9p249}

\begin{abstract}
Nowadays, the technological devices (computer, internet, phones etc.) is rapidly developing and transforming. Especially in the last decades, these changes affected the various fields as well as health, commercial, banking. One of these fields is education. In this study, the technology-driven changes in the educational process were investigated by using university students. This study uses a qualitative method. 35 students are asked about the areas affected most from the ICT focused technological transformations and how these technological transformations affect educational domains. It is concluded as a result of the analyses that the students feel these effects in their lives in such areas as education, communication, family and transportation issues. In addition, it is also concluded that ICT focused transformation is regarded positively in terms of making information access easier, increasing visual learning, increasing educational quality and being economical.
\end{abstract}

Keywords: Technological Transformations, Change and Education, ICT Focused Changes in Education.

\section{Introduction}

Information and Communication Technologies (ICTs) are used more in our daily lives as new technologies develop every day. Many people from every age and every education level use such technologies as mobile phones, computers, the Internet and PDAs. It is seen that the individuals preferring to use these technologies most are the students (TSI, 2011). This development, mainly of ICTs, among the technological devices has affected our lives in many ways. Today, we have been going through a very radical transformation and changing period from education to economy (FernándezMaldonado, 2004; Mioduser, Nachmias, Tubin and Forkosh-Baruch, 2003). Banking transactions conducted by a single button easily, family lives in which the Internet is widely used instead of televisions, communication via $3 G$ compatible mobile phones and other electronically controlled devices have all radically changed our lifestyles especially in the last decade. One of these domains is education. Many different technologies and programs such as smart boards, computers, and the Internet and presentation softwares reshape education systems; and it is even easier to teach via virtual campuses (Anderson and Date-Huxtable, 2011).

\subsection{Importance of the study}

This radical transformation and development process in the technology, especially in ICTs, affect our lives in many different ways. It is important to point out the students' opinions to summarize this issue, as they are the individuals experiencing this change personally in educational domain. Besides, it is also important to state other domains that are affected by the opinions of students in order to indicate how extensive and radical these transformations have been realized.

\subsection{Purpose of the Study}

The purpose of the study is to determine the most affected areas from ICT focused technological transformation in terms of the opinions of the individuals who were primary school students in 1990s and university students in 2010s, and the effects of this transformation in education. Therefore, the students are asked to write down the areas most affected by these transformations of ICT technologies and to give an answer to the question of "What have changed in educational 
domain, do you think, due to these transformations of ICT technologies by taking your previous educational experiences into considerations?".

\section{Method}

In this section, research method, participants, data collection tool and data analysis were given.

\subsection{Research Method}

This study uses a qualitative method in order to determine the effects of ICT focused technological development and transformations in educational domains. Besides, case study pattern is preferred in this study among other qualitative method patterns. A case study is a research pattern used for situations where the object of study is examined through its own context and in which there are no distinctive lines limiting the phenomena and its context and where more than one evidence or data source are available (Yin, 1984; Yildirim and Simsek, 2006). The present situation is determined via the opinions of students.

\subsection{Participants}

The participants of the study involves 35 students from Ahmet Kelesoglu Education Faculty in Necmettin Erbakan University during 2011-2012 education year, registered to a selective course named "Science History" and volunteered to participate in this study. The study uses a qualitative sampling method "purposeful sampling"; and involves the students from Science History course, who have already taken "ICT and Transformation" before. 14 of these students are female $(\% 36,8)$ and 24 of them are male $(\% 63,2)$. Besides, the age range varies between 19 and 24 and the average age is 21.

\subsection{Analysis of Data}

Descriptive statics is used to analyze the demographic data of the participants. Content analysis technique is used to analyze the qualitative data, which is very frequently used in qualitative research. The content analysis is realized by preparing less distinctive themes under theoretical terms and also sub-themes, if there is any (Yildirim and Simsek, 2006). Two expert opinions (one researcher, one expert) are taken for the reliability of the data when coding the data collected from the teachers, preparing themes by using these codes and describing these themes. The reliability of the research data is calculated as $87 \%$ via the formula "Consensus / Dissensus + Consensus) * 100 , put forward by Miles and Huberman (1994) after comparing the responses of the researcher and the expert. The reliable data, which are also available to analyze, are transformed into the codes and then into the themes, the findings are interpreted under the following titles.

\section{Findings}

In this section, the findings obtained from the opinions of the students in terms of the effects of technological transformations in educational domains and the most affected areas from these technological transformations especially in the last two decades are given under the following titles.

\subsection{Areas Affected from Technological Transformations}

The students are asked about the most affected areas from the technology focused changes by taking their previous experiences. There are 23 opinions under 7 different titles for this question. (Table 1).

Table 1. Most Affected Areas For the Students

\begin{tabular}{|l|c|c|}
\hline Affected Areas & f & $\%$ \\
\hline Education & 13 & 25,0 \\
\hline Communication & 9 & 17,3 \\
\hline Family & 7 & 13,4 \\
\hline Transportation & 7 & 13,4 \\
\hline \multicolumn{2}{|l}{} \\
\hline
\end{tabular}




\begin{tabular}{|l|c|c|}
\hline Health & 4 & 7,6 \\
\hline Automotive & 3 & 5,7 \\
\hline Cinema & 3 & 5,7 \\
\hline Public Operations & 3 & 5,7 \\
\hline Entertainment & 2 & 3,8 \\
\hline Agriculture & 1 & 1,9 \\
\hline Total & 52 & 100 \\
\hline
\end{tabular}

When the answers are examined, the most affected area from the technological transformations is seen as the education (25\%) (Table1). This is respectively followed by communication $(17,3 \%)$, family $(13,4 \%)$, transportation $(\% 13,4)$ and health $(\% 7,6)$. Other areas stated herein are automotive $(5,7 \%)$, cinema $(5,7 \%)$, public operations $(5,7 \%)$, entertainment $(3,8 \%)$ and agriculture $(1,9 \%)$ though their proportion is quite low.

\subsection{Technology Focused Transformations in Education}

The answers of students about the effects of ICT focused technological transformation are examined and the findings obtained are given in Table 2 .

Table 2. Effects of Technological Transformation in Education

\begin{tabular}{|l|c|c|}
\hline Effect of Transformation & f & $\%$ \\
\hline Easy Access of Information & 20 & 44,4 \\
\hline Increase in Visual Learning & 14 & 31,1 \\
\hline Increase in Education Quality & 7 & 15,5 \\
\hline Exemption from carrying books and notebooks & 2 & 4,4 \\
\hline Practicality in problem solving & 1 & 2,2 \\
\hline Being economic & 1 & 2,2 \\
\hline Total & 45 & 100 \\
\hline
\end{tabular}

It is seen as an important finding that the transformations by technology use is believed to be advantageous and no negative statement is made in the answers of the students (Table 2). Easy access of information is answered most among the answers of students $(44,4 \%)$. The students think that technology use has changed the educational resources to a great extent. Another important transformation is the increase in visual learning $(31,1 \%)$. Other findings stated more than one person show the statements about the increase in education quality $(15,5 \%)$ and exemption from carrying books and notebooks $(4,4 \&)$. In spite of this, practicality in problem solving and being economic is stated only one person $(2,2 \%)$.

Example statements are given below to indicate the transformations experienced by the students in technologyfocused education;
"We have the opportunity to reach and use the data easily by the development of technology, which was once limited to books." (21, F) (Easy access of information)
"It is no doubt that we experienced positive changes in our lives by the help of technology. Courses have become more comprehensible with visual animations." (22, M) (Increase in visual learning)
"We cover our missing subjects by the help of technology." (22, M) (Increase in education quality)

\section{Results and Conclusion}

The investments made to the ICTs are seen in every aspect of our lives. Besides industrial, agricultural, health, defense and transportation sectors, many areas are now equipped with new technologies. The purpose of these new investments are believed to make our lives more comfortable and lessening the inconveniences of people (Kendall, Kendall and Kah, 2006).

These results are obtained in this study in order to determine the effects of technology on human life and especially on education life in regards of the students at the age of 20 or so:

- According to the students, education is the most affected area from ICT focused technologies. This is followed by communication, family, transportation and health. Other than these, there are five more areas stated by the 
students, but with very low proportions. The answers are important in terms of the needs of students. Whitworth, Price and Randall (2002) state that the opinions of students are affected from their own lives. Therefore, it is very usual to see such issues important as education, family and transportation. As it is also expressed by Mutekwe (2012) it is obvious that information technologies caused fundamental changes in most of the areas and life styles within the society.

- It is seen that the students find the effects of ICT focused transformation positive in terms of education. Although the students have positive opinions, it is important to see that they have no negative sides. The important effects are stated as an easy access of information, increase in visual learning, increase in education quality, exemption from carrying books and notebooks, practicality of problem solving and being economic. These findings correspond to other studies in the literature (Laurillard, 2007; Jimoyiannis and Komis, 2007). Also some researches findings about Internet being the most popular information source especially in the last decade and the developing ICT technologies increasing the quality of education are all supporting students' views (Amenyedzi, Lartey and Dzomeku, 2011; Teo, 2008). On the other hand, ICT oriented transformations also reflected in the standards in terms of applying them into education (NETS-T) determined by International Society for Technology in Education (ISTE). With the developing technology the NETS standards have changed four times from 1993 till now in 1997, in 2000 and the last one in 2008 (NETS, 2013). Standards approve students' views in many transformations such as its role in increasing the quality of education and the importance of visual education.

It is important to see that university students are aware of the ICT focused transformations though under limited areas. When their answers in terms of education are taken into consideration, it is seen that they will be aware of ICT focused transformations and also find these transformation positive after their graduation.

\section{Acknowledgments}

The present study was based on a scientific research project funded by Necmettin Erbakan University Scientific Research Foundation - number 131610043 - called 'Areas Affected Most by The Students from The ICT Focused Technological Transformations and Its Effects on Education'.

\section{References}

Amenyedzi F., Lartey M.N.\& Dzomeku B. M. (2011). The Use of Computers and Internet as Supplementary Source of Educational Material: A Case Study of the Senior High Schools in the Tema Metropolis in Ghana. Contemporary Educational Technology, 2(2), 151-162.

Anderson, A.J., Date-Huxtable, E.M. (2011). ICT-assisted multi-campus teaching: Principles and practice to impact equity of experience for students', Changing Demands, Changing Directions. Proceedings ascilite Hobart 2011, Hobart.

Fernández-Maldonado, A.M. (2004). ICT-related transformations in Latin American metropolises. Doctoral dissertation. Delft University Press, Delft.

Jimoyiannis, A. \& Komis, V. (2007). Examining teachers' beliefs about ICT in education: implications of a teacher preparation programme. Teacher Development. 11(2).

Kendall, K. E., Kendall, J. E., \& Kah, M.O. (2006). Formulating information and communication technology (ICT) policy through discourse: How Internet discussions shape policies on ICTs for developing countries. Information Technology for Development, 12(1), 25-43.

Laurillard, D. (2007). Modelling benefits-oriented costs for technology enhanced learning. Higher Education. 54(1), pp 21-39.

Mioduser, D., Nachmias, R., Tubin, D., \& Forkosh-Baruch, A. (2003) Analysis schema for the study of domains and levels of pedagogical innovation in schools using ICT. Education and information technologies, 8(1), $23-36$.

Mutekwe, E. (2012). The impact of technology on social change: a sociological perspective. Journal of Research in Peace, Gender and Development, 2(11), 226-238.

Teo, T. (2008), Pre-service teachers' attitudes towards computer use: A Singapore survey, Australasian Journal of Educational Technology, 24(4), 413-424.

TSI- Turkish Statistical Institute. Individuals using the computer and internet in the last 3 months by age. Retrieved April 18, 2011, Available from:http://www.tuik.gov.tr/VeriBilgi.do?tb_id=60\&ust id=2, 2011.

Whitworth, J.E., Price, B.A. \& Randall, C.H. (2002). Factors that affect college of business student opinion of teaching and learning. Journal of Education for Business. 77(5). 